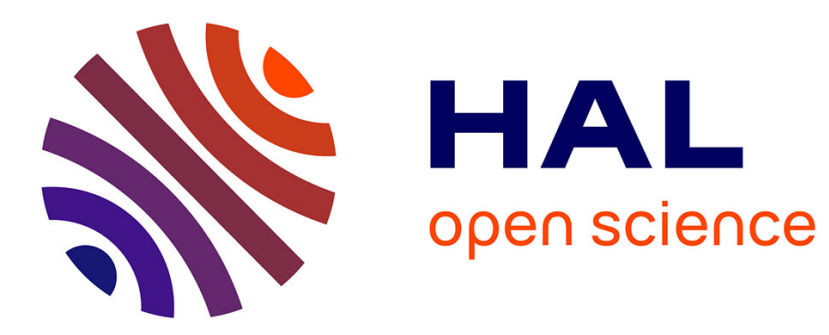

\title{
Private and Public Schools: A Spatial Analysis of Social Segregation in France
}

Pierre Courtioux, Tristan-Pierre Maury

\section{To cite this version:}

Pierre Courtioux, Tristan-Pierre Maury. Private and Public Schools: A Spatial Analysis of Social Segregation in France. 2018. halshs-01823056

\section{HAL Id: halshs-01823056 \\ https://shs.hal.science/halshs-01823056}

Submitted on 25 Jun 2018

HAL is a multi-disciplinary open access archive for the deposit and dissemination of scientific research documents, whether they are published or not. The documents may come from teaching and research institutions in France or abroad, or from public or private research centers.
L'archive ouverte pluridisciplinaire HAL, est destinée au dépôt et à la diffusion de documents scientifiques de niveau recherche, publiés ou non, émanant des établissements d'enseignement et de recherche français ou étrangers, des laboratoires publics ou privés. 


\section{Documents de Travail du

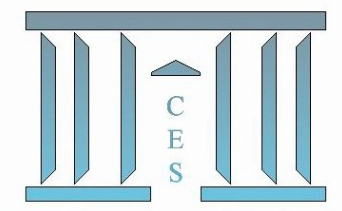

\section{Private and Public Schools: A Spatial Analysis of Social Segregation in France}

Pierre CouRTiouX, Tristan-Pierre MAURY

2018.15

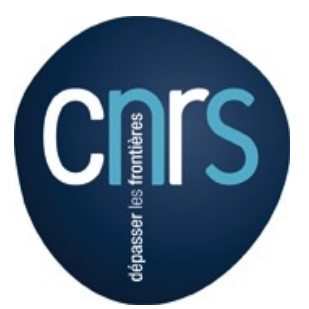




\title{
Private and Public Schools: A Spatial Analysis of Social Segregation in
}

\section{France* $^{*}$}

\author{
Pierre Courtioux ${ }^{\dagger} \&$ Tristan-Pierre Maury ${ }^{\ddagger}$
}

May 14, 2018

\begin{abstract}
This article provides a geographical and urban analysis of the contribution of differences in enrollment between the public and private sectors to social segregation in French middle schools. Using the mutual information index, we show that the contribution of public/private divergences is higher in middle-sized urban areas and center municipalities. These geographical areas, however, are not those where social segregation is the highest, nor those where the private sector is commonly regarded as the main cause of segregation. Moreover, the gaps between the public and the private sectors are stronger at the local level. This confirms the idea that the private sector is indeed a tool for circumventing France's School Map (la carte scolaire) for allocating places to pupils and that private schools create additional social differences the smaller spatial scale.
\end{abstract}

\section{A Introduction}

The spatial inequalities of schooling is an issue that is on the political agenda of many countries and has led to the development of research which stresses the various aspects of the links between geography and education (Butler and Hamnett, 2007). One of these aspects is the impact of parental schooling strategies on social segregation and their consequences for educational attainment (Hamnett et al. 2007). Given the importance of this issue in the national political agenda, French policy is changing. Indeed, the government recently launched a program to reduce the level

\footnotetext{
*The authors thank Amelie Robinette for valuable research assistance.

${ }^{\dagger}$ EDHEC Business School and Centre d'Economie de la Sorbonne

$\ddagger$ EDHEC Business School
} 
of segregation in middle school. ${ }^{1}$. The geography literature has stressed several reasons that could explain the changes in social segregation at school. These include changes in the social composition of a given area (Gulson, 2007; Lees and Ley, 2008) as well as shifts in the allocation of pupils in a given area that could be driven by changes in family schooling choices (Gramberg, 1998; Thrupp 2007; Murnane and Reardon, 2017). We call this latter phenomenon the middle-school enrollment arrangement, which differs greatly across countries.

The middle-school enrollment arrangement in France is characterized by at least two important features, namely the School Map and a contracting policy with private schools. ${ }^{2}$ The School Map (la carte scolaire) was progressively implemented during the 1960s in order to plan and accompany the extension of public education induced by the raise of the mandatory school leaving age from 14 to 16 . The aim of the School Map is to allocate students to a given public school on the basis of their home address. Any student whose family resides in the geographical catchment area of a given school must theoretically be enrolled in that school. In this view the French School Map is more restrictive for school choice than for instance the English allocation system described in Allen (2007). This education policy was legitimized by the principle of homogeneity in the supply of education (Merle, 2012). The idea that all schools supplied a similar education in terms of school programs, the number and experience of teachers, etc. was well established at that time. However, the allocation of a given pupil according to her/his home address to a given public school based on the School Map is far from being systematic, as it is possible for families to develop strategies to escape the School Map. For instance, derogations or waivers can be negotiated by parents with the Local Education Authority (LEA) and the school on the basis of several criteria: health (for students with a disability or requiring significant medical care near the requested school), fellowship, family situation (for students whose siblings are already in the requested school) or according to a student's specific educational background (for example, if a student has taken courses in a particular language in primary school, but the secondary school in her/his area does not offer courses for this language). In addition, when a request for formal derogation is unlikely to succeed, some parents manage in declaring a false address in order to escape the school corresponding of their catchment area. Many families, aware that the territorial homogeneity of the education supply is far from being perfect, resort to these formal (or informal) derogation strategies.

\footnotetext{
${ }^{1}$ Following a report by French Members of Parliament in 2015, showing that in France social segregation at school was increasing, the Education Ministry launched an experimental program in some local areas in 2016, in order to reduce segregation in middle school. This program aims at increasing social mixing at school and preventing segregation by dispersing and integrating the poorest pupils of a given geographical area among a set of schools. It comes close to some of the new gentrification policies described by Lees and Ley (2008).

${ }^{2}$ The Priority Education Area (PEA) program aims at enhancing equal opportunity by concentrating means and specific education programs in disadvantaged geographical areas, and it is another specific feature of the French school system. However, in order to limit the scope of the analysis, we make no distinction here between PEA and non-PEA schools in the public sector.
} 
Turning to the private school sector is an alternative schooling strategy for families who want to escape the School Map. If parents decide to enroll their child in a private school, they will have to pay tuition fees (while public schools are free). But this strategy to avoid a given school is not necessarily very costly for the families. Since 1959 and the Debré Law, the private sector, which is historically almost exclusively composed of Catholic schools, has been part of France's public education system (Poucet, 2012; Thélot, 2013). ${ }^{3}$ Under contract, private schools agree on teaching the national academic curriculum and they benefit from public subsidies to pay for the entire teachers' wage bill and some operating costs. This high level of state subsidy does not mean that private schools are free, but tuition fees differ greatly across schools since they depend on the living standards of the geographical area. For instance, the fees tend to be higher in city centers. While some local policies do support inclusive enrollment in these schools (scholarships or free fees programs for families in need, etc.), the need to pay fees does lead private schools to enroll more pupils from favored social backgrounds on average. Previous research, for instance the Los Angeles case study by Andre-Bechely (2007), have shown that enlarging school supply may be inefficient in favoring social mixing, as some families do not have the necessary resources (time, transport, etc.) to have a real choice. In the French case, it is also important to note that the demand for these private schools largely exceeds the number of places available. Parents often have to take steps well in advance to register their children. Again, this often favors wealthy families with better local networks that help them to take all the necessary steps to have their children enrolled in a private school. Even if there is a great heterogeneity among private schools the "religious" or "religion" factor (as defined for example by Cohen-Zada and Sander (2008) for their analysis of the United States) is not discriminatory in the French case. This specific national context explains why France's private (almost exclusively Catholic) schools educate almost $20 \%$ of pupils in middle schools. At the same time, the school re-location phenomenon described by Gamsu (2016) for the London area is rather marginal in France, even for the private sector.

The issue of social segregation at school is highly sensitive in the French education policy debate. Yet, the number of academic studies on this subject remains limited. A few studies agree that levels of social segregation are high in France and that they have been at least stable over the last ten years, or even slightly increasing (Ly and Riegert, 2015, Ly, Maurin and Riegert, 2014). In this debate, one of the main political issues is to what extent the private sector is responsible for social segregation and how far it should be included in the School Map to reduce social segregation. To our knowledge, there are only two studies (Givord et al., 2016a, 2016b) which deal with this issue

\footnotetext{
${ }^{3}$ In France, being from a Catholic family is not a strong determinant of enrollment in a Catholic middle school. From a legal point of view, school directors are not allowed to select their pupils on a religious basis. More generally, religious activities or courses are not mandatory (Sunday school, etc.) for most private schools which are under contract to the State. France's national academic curriculum sets out the core courses private schools much teach in order to receive large State subsidies (see below).
} 
using French data. The authors estimate the evolution of social segregation in French middle-schools since 2004 and measure the contribution of the gaps between the public and the private sector to this segregation. ${ }^{4}$ They show that an increasing share of social segregation is due to the differences between the social composition of public and private schools. They also provide evidence that the private sector alone is increasingly heterogeneous. Actually, these studies mainly put forward national results. Some measures of segregation levels for large academies or regions are produced, but this is not done in a complete and systematic way. This does not allow the structure of the gaps between the public and private sectors to be described geographically. Other studies have carried out a more comprehensive spatial analysis of the evolution of social segregation (Ly and Riegert, 2014, Ly et al. 2014), but they do not distinguish between the public and private sectors.

This paper is a first step in the direction of a geographical and urban analysis of the social differences observed in France between public and private schools. In this perspective, our contribution is close to the relatively recent US literature measuring segregation (either residential segregation or school segregation) across a range of spatial scales. For instance, Fischer et al. (2004) measure residential segregation in the United States and present a new method for attributing segregation to nested geographical levels. Segregation is then additively decomposed into contributions of regional, metropolitan, center city/suburban, place, and tract segregation. Lee et al. (2008) or Reardon et al. (2009) describe patterns and determinants of racial segregation in large US metropolitan areas and indicate how segregation changes as one moves from small to large spatial scales. In the same line, Lichter et al. (2015) propose broadening the spatial lens for studying racial segregation using U.S. data. They decompose segregation both within and between metropolitan cities and suburbs.

From a methodological point of view, we rely on the contributions of Frankel and Volij (2011) and Reardon and Firebaugh (2002) and exploit the additive decomposability property of the mutual information index. We are then able, after measuring social segregation in French schools at the national level, to break down these levels of segregation according to: i) a geographical dimension (with different nested levels such as the Local Education Authority, the urban area, or the municipality); ii) an urban dimension (distinguishing rural/isolated municipalities/center municipalities/suburban municipalities), and iii) and of course a school's sector (public/private). All these dimensions are crossed in the study: i.e., at each spatial or urban scale, we focus on both the segregation level, but also on the contribution of public/private social differences to this level of segregation. More precisely, our contribution is threefold. First, we map the gaps between public and private middle schools in French regions. It is well-known that

\footnotetext{
${ }^{4}$ Due to the lack of ethnic data, the literature based on French data essentially measures social segregation at school, and not racial segregation as usually happens with US data. A precise definition of what is meant by social segregation will be given in the Data and Method section.
} 
levels of segregation vary greatly from one region to another in France (they are notably higher in the Paris region than in the rest of the country.) Our study shows that levels of segregation due to differences between public and private schools are also geographically heterogeneous. The differences are more pronounced in France's northern regions, i.e., not necessarily in the most segregated part of the country. Second, we provide evidence of a clear pattern of the contribution of the public/private gap to local segregation, according to the size of the urban area and the location of the municipality in the urban area. Surprisingly, the contribution of the public/private gap is bigger in middle-sized urban areas and in center municipalities, while segregation is itself at its maximum in very large urban areas and in suburban municipalities. Third, using the decomposability properties of our segregation index, we estimate the contribution of public/private gaps measured at different geographical levels to national segregation. For example, we compare the contribution of nationwide public/private differences to the contribution of within-municipality public/private differences. It appears that local differences contribute more to national segregation. Public and private schools are no more alike if they are actually neighbors. This shows that the process of allocating students between the two sectors is done on a small geographical scale. In other words, public/private competition is local. The contribution of the gap between public and private schools to segregation is therefore the result of parental choice carried out within in a specific district (e.g., parents enroll their children in the local private school to escape to the local public school) rather than of social differences across districts. The geographical distribution of private schools not only follows the geographical distribution of families' social backgrounds (even if private schools are generally more present in rich areas). Instead, the distribution of private schools creates new social divergences within regions or municipalities.

Two conclusions for the French education policy debate can be drawn from these results. First, while the private sector is generally held responsible for the social segregation observed in major urban areas (Paris, Lyon and Marseille) and especially in their suburbs, our results show that the role of the private sector, without being negligible, is much less important there than in other urban centers or other regions. Second, the gaps between the public and private sectors are stronger at the local level. This confirms the idea that on average the private sector creates additional social differences at small spatial levels, and is potentially a tool for circumventing the School Map. ${ }^{5}$ As in the cities of other countries (e.g., Finland (Bernelius and Vaattovaara, 2017)) there is evidence of increasing school segregation at the local level. However, it is specific to France that this trend is not only explained by residential choices but also by some changes in the enrollment composition of private schools, in some particular areas that we identify.

The rest of the paper is organized as follows. The data and methodology are presented in the Section B. The

\footnotetext{
${ }^{5}$ Our results show that the impact of the policy launched in 2017 and which aims at reducing social segregation at school level for several selected, small geographical areas may be seriously limited if the policy is extended nationally by focusing on the public schools of the School Map.
} 
evolution of the national levels of school segregation is detailed in the next section. Regional disparities in school segregation are discussed in section D. The contribution of public/private differences to segregation is presented in Section E. A spatial decomposition of inter-sector segregation is given in the following section. Section G concludes.

\section{B Data and Method}

\section{B.1 data}

In France, pupils spend five years in primary school, from age 6 to 11, then four years in middle school (collège), from age 11 to 15 . Finally, most pupils then go on to spend three years in high school (lycée), from age 15 to 18 . Here, we focus on middle school students. This choice is motivated by several reasons, beginning with the fact that comprehensive administrative data are available for secondary education (see below). Furthermore, all French children must pursue their studies until the end of middle school because education is compulsory until the age of 16 .

We use comprehensive data from the SCOLARITE information system, provided by the French network of data centers for social sciences. These data come from the Central Schooling Base (Base Centrale de Scolarité), which is itself taken from the more general administrative database (Base Elèves Académiques \} for information about students, and a school database (Base Elèves Etablissement) for information about schools. For each year from 2004 to 2016 , we have a file containing administrative information as well as some geographical characteristics of each middle school in France ("school file"). In particular, we know if it is a private or a public school. The geographical location of schools is available at the municipal level. However, it is not possible to distinguish various very close-to-home neighborhoods for pupils attending the same school, as in Webber and Butler (2007). Moreover, in contrast to the studies by Gordon and Monastiriotis (2006) or Webber and Butler (2007), it is not possible with our database to link the level of social segregation with educational output.

"Student files" provide socio-demographic characteristics for each individual pupil in the total middle school population, with information on: gender, nationality, social background, place of residence, as well as information about each pupil's schooling (study program, options, foreign languages, etc.). An identifier of the establishment makes it possible to match the "school" and "student" files. For example, for 2004, we have individual information on 3,252,380 students enrolled in 6,924 middle schools. For this study, we have selected the schools present each year over the entire period 2004-2016, which cuts the number of schools in our sample to 6,722.

In this article we distinguish between four different social backgrounds based on the occupation (professions et 
catégories socio-profesionnelles) of the parent legally responsible for the student. This social background definition is usual in the academic literature available. It is also used by the French Ministry of Education for policy evaluation purposes. The four social backgrounds are divided into: "disadvantaged backgrounds", "intermediate backgrounds", "advantaged backgrounds", "highly advantaged backgrounds". The "disadvantaged" category concern families where the head is an unskilled blue collar worker, jobseeker or inactive. The "intermediate" category is for farmers, craftsmen, tradesmen, unskilled white collar workers (administrative or public sector employees without any managerial responsibilities). The "advantaged" category is for clergymen, foremen, technicians and associated professionals, clerical and service workers; in the usual French occupation classification they are called "intermediate professions" (professions intermédiaires) meaning that they have some managerial responsibilities. The "highly advantaged" category is for CEOs, managers, executives, higher education professors and liberal professions.

\section{B.2 measurement of segregation}

There are many segregation indices, the characteristics of which may strongly differ (see, for example, Massey and Denton, 1988). For instance Burgess et al. (2005) and Gordon and Monastiriotis (2006) use the dissimilarity index. For the purposes of this study, we have very specific needs about the desirable properties of the segregation index. First, like Frankel and Volij (2011) or Reardon and Firebaugh (2002), we place ourselves immediately in the context of a multi-group analysis, since the number of groups is 4 here, whereas many indices are only suitable for up to two

groups. Second, since we want to study segregation at several levels simultaneously (at the establishment level of course, but also at the sector, i.e., public vs. private, level), we must take the decomposability properties of the index into account. For instance, we will be interested in investigating how much of the social segregation between schools in France is due to segregation between sectors (i.e., between public and private schools) and how much is due to segregation within sectors.

We focus on the mutual information index since it satisfies most of the required properties. Let $N$ be the total number of students in the French middle schools surveyed. This population is divided into $K$ units (i.e., $K$ schools) with $N^{k}$ the number of students in school $k(k=1, \ldots, K)$. Let $G$ be the number of groups (here, social categories). As explained in the data section, $G=4$. The total number of students belonging to the group $g$ is $N_{g}(g=1, \ldots, 4)$. We set $g=1$ for the "highly advantaged" group, $g=2$ for the "advantaged" group, $g=3$ for the "intermediate" group and $g=4$ for the "disadvantaged" group. $N_{g}^{k}$ is the number of students in group $g$ in school $k$.

$p_{g}$ is the overall proportion of students belonging to group $g, p_{g}=N_{g} / N$ and $p^{k}=N^{k} / N$ is the share of students enrolled in school $k$, whereas $p_{g}^{k}=N_{g}^{k} / N^{k}$ is the proportion of group- $g$ students in the school $k$. $P$ is the 
distribution of the different groups in the population, $P=\left(p_{1}, p_{2}, p_{3}, p_{4}\right)$ and $P^{k}$ is the distribution of the different groups in the school $k, P^{k}=\left(p_{1}^{k}, p_{2}^{k}, p_{3}^{k}, p_{4}^{k}\right)$.

The mutual information index $M$ is given by

$$
M=h(P)-\sum_{k=1}^{K} p^{k} h\left(P^{k}\right)
$$

where $h(P)$ is the entropy of the distribution $P$

$$
h(P)=\sum_{g=1}^{4} p_{g} \ln \left(\frac{1}{p_{g}}\right)
$$

The entropy is always positive and is maximal when all the proportions are equal $\left(p_{1}=\ldots=p_{4}\right) . M$ is equal to zero (no segregation) when the distribution of groups in each school is consistent with the national distribution $\left(P^{k}=P\right.$ and hence $h\left(P^{k}\right)=h(P)$ for all values of $k$ ). For example, if we assume that the national distribution is: $20 \%$ of disadvantaged students, $30 \%$ of intermediate students, $10 \%$ of advantaged students and $40 \%$ of highly advantaged students, then $M=0$ if we observe this distribution in each school in France. In contrast, the social segregation is maximal when each school only educates students from a single group. In the previous example, it would mean that $20 \%$ of schools only have disadvantaged students, $30 \%$ only intermediate students, etc. In that case, $h\left(P^{k}\right)=0$ for each $k$ and $M(X)=h(P)$.

The mutual information index therefore has values from 0 to $h(P)$. The maximum value of the index depends on the distribution of the reference population: this may render the interpretation of the index difficult. This is why it is more common to use a standardized version of this index - the Theil index - which is simply equal to the mutual information index divided by its maximum value. The Theil index then takes its values between 0 and 1 . However, $M$ has better decomposability properties. Notably, as demonstrated by Frankel and Volij (2011), the mutual information index satisfies the strong school decomposability (SSD), which is a critical property for our purpose. ${ }^{6}$

The SSD property implies that it is possible to decompose additively the total segregation at different levels. For example, let $X$ and $Y$ be two school clusters (these may be geographical areas or different sectors, the public sector and the private sector for example). $X \cup Y$ is the union of these two sectors (all schools, public and private combined). Let $c(X)$ (resp. $c(Y))$ be the fictitious school resulting from the union of all schools in $X$ (resp. in $Y$ ). $M$ satisfies the SSD property:

$$
M=M(c(X) \cup c(Y))+\frac{N_{X}}{N_{X}+N_{Y}} M(X)+\frac{N_{Y}}{N_{X}+N_{Y}} M(Y)
$$

where $M(X)$ (resp. $M(Y)$ ) is the mutual information index in cluster $X$ (resp. $Y$ ). $N_{X}$ (resp. $N_{Y}$ ) is the number of students in cluster $X$ (resp. $Y$ ). As shown by equation (B.3), the total segregation level, $M$, is the sum of three

\footnotetext{
${ }^{6}$ It also satisfies the strong group decomposability (SGD) property which will not be used here (e.g., Frankel and Volij, 2011).
} 
components: the level of segregation between $X$ and $Y, M(c(X) \cup c(Y))$, the (weighted) level of segregation within $X, M(X)$, and the (weighted) level of segregation level within $Y, M(Y)$. Significantly, the weights depend only on the relative sizes of the two clusters and not on their composition. It is therefore possible to calculate the share of total segregation due to differences between or within clusters.

For our purposes, it is also be interesting to extend the number of clusters (for example, by crossing the sector with a geographical variable). In this case, the SSD property still applies

$$
M=M\left(c\left(X_{1}\right) \cup c\left(X_{2}\right) \cup \ldots \cup c\left(X_{C}\right)\right)+\sum_{c=1}^{C} \frac{N_{X_{c}}}{N} M\left(X_{c}\right)
$$

where $C \geq 2$ is the number of clusters. For a complete demonstration, please refer to Frankel and Volij (2011).

Moreover, it is possible to proceed to a nested decomposition of the segregation level. Assume for example that there are two geographical divisions $A$ and $B$ and two sectors $X$ and $Y$ (e.g., public and private). For instance, $X_{A}$ is the set of public schools located in $A$. Then $M$ may be expressed as follows

$$
\begin{aligned}
M= & M(c(A) \cup c(B))+\sum_{R=A, B} \frac{N_{R}}{N_{A}+N_{B}} M\left(c\left(X_{R}\right) \cup c\left(Y_{R}\right)\right)+ \\
& \sum_{R=A, B} \frac{N_{R}}{N_{A}+N_{B}}\left[\frac{N_{R_{X}}}{N_{R_{X}}+N_{R_{Y}}} M\left(X_{R}\right)+\frac{N_{R_{Y}}}{N_{R_{X}}+N_{R_{Y}}} M\left(Y_{R}\right)\right]
\end{aligned}
$$

In the RHS of equation (B.5), the first term corresponds to the level of segregation between regions $A$ and $B$ and the second term to the level of segregation between the public sector $X$ and the private sector $Y$ within the same geographical division. This term may be compared to $M(c(X) \cup c(Y))$ in equation (B.3) to see if the geographical scale is relevant when measuring the contribution of the level of segregation between $X$ and $Y$ to the national level of segregation $M$. The last term in equation (B.5) is the level of segregation between schools (here the school is the lowest geographical scale) within the same geographical division and the same sector.

\section{School Segregation was Fairly Stable between 2004 and 2016}

Before we focus on the gaps between the public and the private sectors, we begin with a more general descriptive analysis of the evolution of social segregation in French schools. Table 1 gives the annual evolution of the share of each social group, as well as the evolution of the (national) mutual information index $M$. 
Table 1. Share of Social Groups and Segregation Level

\begin{tabular}{llllllllllllll}
\hline Year & 2004 & 2005 & 2006 & 2007 & 2008 & 2009 & 2010 & 2011 & 2012 & 2013 & 2014 & 2015 & 2016 \\
\hline group 1 & 18.86 & 19.34 & 19.42 & 19.76 & 20.79 & 21.17 & 21.45 & 21.49 & 21.57 & 21.64 & 21.80 & 21.92 & 22.12 \\
group 2 & 7.69 & 7.56 & 7.48 & 7.36 & 6.07 & 5.82 & 5.71 & 5.62 & 5.54 & 5.45 & 5.38 & 5.35 & 5.33 \\
group 3 & 33.39 & 33.52 & 33.88 & 34.43 & 34.23 & 34.47 & 34.55 & 34.49 & 34.44 & 34.36 & 34.25 & 34.07 & 33.96 \\
group 4 & 40.07 & 39.58 & 39.21 & 38.45 & 38.91 & 38.55 & 38.29 & 38.40 & 38.45 & 38.55 & 38.57 & 38.66 & 38.59 \\
\hline$M$ & 0.1253 & 0.1273 & 0.1262 & 0.1253 & 0.1260 & 0.1262 & 0.1260 & 0.1268 & 0.1265 & 0.1260 & 0.1274 & 0.1291 & 0.1306 \\
\hline
\end{tabular}

Source: Base Centrale de Scolarité - Authors' calculations

Note: Calculations made with the total population of students in middle schools between 2004 and 2016

Group $i$ is the percentage share of students in group $i$. Group $1=$ "highly advantaged", group $2=$ "advantaged" group $3=$ "intermediate", group $4=$ "disadvantaged". $M$ is the level of the mutual information index ${ }^{7}$

The relative sizes of the social groups changed slightly between 2004 and 2016. The proportion of students with a "highly advantaged" background increased from $18.86 \%$ to $22.12 \%$, while the proportions of students with an "advantaged" and a "disadvantaged" social background decreased (respectively from 7.69\% to 5.33\%, and from $40.07 \%$ to $38.59 \%$ ). The relative size of the "intermediate" group of students remained fairly stable. This increase in the proportion of favored students has already been documented in the literature (see Givord et al., 2016a). From a statistical point of view, it is important to note that these variations are limited enough not to lead to skewed interpretations of the evolution of $M$. In fact, even if $M$ verifies a large number of key properties, it does not fulfill the condition of "composition invariance", CI. As explained by Frankel and Volij (2011), the CI property ensures that if the relative sizes of one or more groups change, the segregation index remains unaffected. Put differently, the segregation index is not sensitive to the composition. The mutual information index does not theoretically satisfy the CI property. However, as explained by Givord et al. (2015), the degree of sensitivity of entropy indices in general (and the mutual information index in particular) to a population's composition has been tested empirically and is not significant. $^{8}$

\footnotetext{
${ }^{7}$ Since we work with an almost exhaustive dataset (the entire population of middle school students between 2004 and 2016 ), no standard deviation can be calculated.

${ }^{8}$ Actually, the only indexes matching the CI property are the Atkinson indexes (either symmetric or asymmetric). We ran the same calculations with Atkinson indices and found again that segregation remained quite steady until 2014 and then slightly increased in 2015 and 2016. We are thus relatively confident the time profile of $M$ reflects the evolution of social segregation and is not related to change in the composition of the population over time.
} 
According to the mutual information index $M$, levels of social segregation have not changed significantly since 2004. As we said before, the index is not standardized. Also, it is useless to try to interpret the values taken by $M .^{9}$ Nonetheless, the evolution of the index is instructive: it remained almost constant for ten years (from 2004 to 2014) before experiencing a slight increase in 2015 and 2016. Over the whole period considered, it therefore seems that no significant upward or downward trend in social segregation can be detected. Students from privileged backgrounds are more and more numerous in France, but this did not alter the differences in the distribution of social groups between schools.

\section{Regional Disparities are Growing}

We now wish to break down the national mutual information index and proceed with a spatial analysis. We work with several geographic divisions: Local Education Authorities (the widest level), départements (an intermediate level: each Local Education Authority is made up of 1 to 4 départements) and municipalities or communes (the smallest level: there are more than 36,000 municipalities). We do not work with all these levels simultaneously because they are not all relevant for the analysis conducted. Each geographic division will be defined more precisely afterwards when it will be used. In addition, we will use variables related to the degree of urbanization of the municipality in which the school is located: rural, isolated or, if urban, municipality-center or suburban; the size of the urban area in which the municipality is located, etc. The variables corresponding to the geographical division and those related to urbanization will be frequently analyzed simultaneously throughout the article.

Education in France is supervised at the local level by the Local Education Authorities - LEA - or \textit $\{$ Académies\} (Fack and Grenet, 2010). There are 31 LEAs in France (including those in the overseas territories). The assignment of students and the allocation of funds to school is conducted by the LEA in its own territory. As explained by Fack and Grenet (2010), since human and financial resources depend mostly on school enrollment, spending per student and the number of teachers per student are quite homogenous across public schools, within a given LEA. LEAs may therefore be an appropriate level for a geographical analysis. It is interesting to examine which part of the segregation level $\mathrm{M}$ is due to between-LEA vs. within-LEA discrepancies. Moreover, we would also like to decompose the level of social segregation according to the degree of urbanization. From this perspective, we use two key variables: (1) a

\footnotetext{
${ }^{9}$ However, we also calculated levels of segregation with some normalized indices (Atkinson, Theil, Gini multigroups, Dissimilarity or Exposure). According to the index chosen, the segregation varies between 10 and $15 \%$ (where $0 \%$ corresponds to a situation without segregation) with, as for the mutual information index, almost no evolution from 2004 to 2016 . These complementary results are available upon request.
} 
variable listing the range of the size of Urban Area ${ }^{10}$ (number of inhabitants) where each school is located; ${ }^{11}(2)$ a variable distinguishing rural areas, isolated municipalities, suburban municipalities and center municipalities ${ }^{12}$.

Table 2 provides all these decompositions using the SSD property of the mutual information index. First, we note that the share of social segregation due to differences across LEAs has changed notably over the period. It increased by almost two percentage points between 2004 and 2012, before falling by about 50 basis points between 2012 and 2016. Hence, it means that until 2012, social segregation due to differences between LEAs had increased, while the mutual information index remained steady. This may mean, for example, that some LEAs have received increasing proportions of students from privileged backgrounds, while others have seen their share of disadvantaged students increase. In terms of social composition, LEAs have moved away from each other until 2012. This probably reflects the residential migration trends in France over this period. In fact, it is unlikely that many families will take administrative steps to send their children to schools in LEAs other than where they live. ${ }^{13}$ Some French regions are getting wealthier relative to others, due to migratory trends and this phenomenon has an impact on schools' composition. At the same time, it also means that the composition of the schools within each LEA has become more homogeneous from 2004 to 2012 (although, in 2012, intra-LEA differences still account for more than $80 \%$ of total segregation). By contrast, after 2012, within-LEA heterogeneity increased markedly ( $M$ has increased and, simultaneously, segregation due to discrepancies between LEAs has decreased). We will return below to this trend break between 2012 and 2016.

\footnotetext{
${ }^{10}$ In France, the definition of an urban area (unité urbaine) is based on the continuity of construction and the number of inhabitants. An urban unit is a municipality or group of municipalities with a continuously constructed area (no more than 200 meters between two buildings) and with a population of at least 2,000 .

${ }^{11}$ More precisely, this variable distinguishes rural areas, urban areas of less than 5,000 inhabitants, between 5,000 and 10,000 , between 10,000 and 20,000, between 20,000 and 50,000, between 50,000 and 100,000, between 100,000 and 200,000, between 200,000 and 2,000,000 inhabitants, and finally the Paris UA.

${ }^{12}$ Municipalities that are not part of an urban area are considered as rural: municipalities without a continuous construction area of 2,000 inhabitants, and those with less than half of the municipal population in a continuous construction area. If the urban unit is made up of a single municipality, it is called an isolated municipality. As a result, isolated municipalities are usually small urban units.

Finally, within large urban units, we can distinguish center municipalities from suburban municipalities. If a municipality represents more than $50 \%$ of the population of the metropolitan area, it is the only center municipality. Otherwise, all municipalities that have a population greater than $50 \%$ of that of the most populated municipality, are city centers (including the most populated municipality). The other municipalities of the urban area are suburban municipalities.

${ }^{13}$ It is indeed more difficult to obtain a dérogation (the enrollment of a student in a school other than her assigned school in the catchment area where she lives) in the LEA where the family lives rather than in another LEA.
} 
Table 2. Geographical Decomposition of $M$

\begin{tabular}{|c|c|c|c|c|}
\hline Year & 2004 & 2008 & 2012 & 2016 \\
\hline$M$ & 0.1253 & 0.1260 & 0.1265 & 0.1306 \\
\hline between-LEAs & $16.33 \%$ & $17.59 \%$ & $18.17 \%$ & $17.63 \%$ \\
\hline between-UA sizes & $9.97 \%$ & $10.33 \%$ & $10.01 \%$ & $8.98 \%$ \\
\hline between-urban type & $4.21 \%$ & $4.33 \%$ & $5.74 \%$ & $5.67 \%$ \\
\hline
\end{tabular}

Source: Base Centrale de Scolarité - Authors' calculations

Note: $M$ is the level of the mutual information index (see Table 1);

"between-LEAs" is the share (\%) of $M$ due to gaps across LEAs;

"between-UA sizes" is the share (\%) of $M$ due to gaps across UA sizes;

"between-urban type" is the share (\%) of $M$ due to gaps across rural/isolated/

suburban/center municipalities

We find similar results with the variables relating to the size of the urban area and the degree of urbanization. Differences between small and large UAs or between rural/isolated and suburban/center municipalities grew until 2012, but narrowed between 2012 and 2016. It should be noted that the fall in 2016 of segregation between-UA sizes is more pronounced than for the other variables, while it remained almost constant for the segregation between-urban types.

Figure 1 gives the values of $M$ for each of the 96 administrative districts (départements) of metropolitan France in 2004 and 2016. The maps show unambiguously that départementswith high levels of segregation are those with a large UA (Paris, Lille, Lyon, Marseille, etc.). Social segregation is therefore mostly an urban phenomenon.

\section{[ Insert Figure 1 here, Map of France : $M$ by département ]}

\section{E Private and Public Schools Move Away from Each Other}

\section{E.1 private schools get richer on average}

We will now conduct a comparative analysis of public and private schools. First, we compare the social composition of students in the two sectors. Results are summarized in Table 3. It appears that around $20 \%$ of students are enrolled in the private sector. This figure was relatively steady over the time period studied (more precisely, it was almost $20 \%$ in 2004 and slightly above $21 \%$ in 2016). Moreover, the share is almost equivalent for the other levels of non-tertiary 
education. This level is above the OECD average (OECD, 2011), equivalent to Denmark, higher than Germany, Italy, United Kingdom, Canada and the United States, but below Japan, Spain, Australia, Ireland and the Netherlands. As the issues concerning private schooling, their financing and their impact on education attainments may differ across countries, the source of debate in France comes from the fact that the private sector educates relatively more students from privileged backgrounds than does the public sector, while at the same time benefitting from State subsidies. For example, in 2016, the share of students with a "highly advantaged" background was close to $36 \%$ in the private sector, but only $18 \%$ in the public sector. In contrast, students with a disadvantaged background are overrepresented in public schools (around 43\%), compared to the private sector (only 20\%). In addition, this trait increased significantly between 2004 and 2016: the share of disadvantaged students in the private sector fell from $25.50 \%$ to $20.50 \%$, while remaining almost steady in the public sector.

Table 3. Distribution of social backgrounds per sector

\begin{tabular}{ccccccc}
\hline Year & Sector & highly advantaged & advantaged & intermediate & disadvantaged & $\%$ priv \\
\hline \multirow{2}{*}{2004} & Public & $16.29 \%$ & $7.54 \%$ & $32.49 \%$ & $43.68 \%$ & \\
& Private & $29.21 \%$ & $8.28 \%$ & $37.00 \%$ & $25.50 \%$ & $19.90 \%$ \\
& Total & $18.86 \%$ & $7.69 \%$ & $33.86 \%$ & $40.07 \%$ & \\
\hline \multirow{2}{*}{2016} & Public & $18.34 \%$ & $4.82 \%$ & $33.42 \%$ & $43.43 \%$ & $21.09 \%$ \\
& Private & $36.26 \%$ & $7.26 \%$ & $35.97 \%$ & $20.50 \%$ & $38.59 \%$ \\
\hline
\end{tabular}

Source: Base Centrale de Scolarité - Authors' calculations. Note: The share of

students with a highly advantaged background in the public sector was $16.29 \%$ in 2004 .

The share of students enrolled in the private sector in 2004 was $19.90 \%$.

As expected, this progressive "specialization" of each sector (private schools for privileged students and public schools for less disadvantaged students) has led to an increase in the level of social segregation due to the differences between sectors. Figure 2 confirms this assertion. Cross-sectoral gaps accounted for $11.31 \%$ of the total segregation in 2004 , but nearly $19 \%$ in 2016 . This increase is almost continuous. Thus, in spite of the quantitative prevalence of the public sector in France, differences between private and public schools are still responsible for almost one-fifth of the segregation observed. These results confirm those obtained by Givord et al. (2015).

\section{[ Insert Figure 2 ]}




\section{E.2 Private/Public Differences Are Not Spatially Homogenous}

At this stage, we would like to highlight the real nature of the discrepancies between private and public schools. Indeed, to our knowledge, no study has ever attempted to describe geographically the public/private gap. Tables $4 \mathrm{a}$ and $4 \mathrm{~b}$ display the decomposition of the level of segregation due to public/private differences according to two of the spatial/urban variables already presented. First, in Table 4a, we show that the mutual information index varies strongly with the size of the urban area. As expected, it is rather small in rural areas or small urban units (around 0.06). By contrast, it is approximately three times higher in the Paris Agglomeration or in other large urban units and well above the national level. Hence, segregation is low in rural or sparsely populated areas and large in densely populated areas. Broadly speaking, it seems that the contribution of differences between the private and the public sectors also grows with the size of the urban area (we will see further that things are more complicated among medium and large UAs). This contribution accounts for less than $10 \%$ of the observed segregation in UAs with less than 10,000 inhabitants, but always more than $20 \%$ in UAs with more than 20,000 inhabitants. The increase in the segregation level within larger settlements is consistent with the findings in other countries (for instance, Gordon and Monastiriotis, 2006).

The small contribution of differences between private and public schools in less populated areas may be due to three factors. Firstly, the size of the private sector is relatively small in rural areas. As shown in Table 4a, between $10 \%$ and $20 \%$ of students living in UAs of less than 10,000 inhabitants are enrolled in the private sector, compared to more than $20 \%$ in larger UAs. A larger private sector may technically contribute to a bigger value of $M(c(X) \cup c(Y))$. It is a pure size effect: if the private sector is very small, $M(c(X) \cup c(Y))$ will also be small even if the few private schools were very different from the others. Here, we show that the share of the private sector is indeed a little bigger in large UAs than in small UAs or rural areas. However, this effect is far too weak to explain the tremendous differences observed in $M(c(X) \cup c(Y))$ according to the UA size. Most of the effects obtained come from differences in the social distribution of families between sectors. Secondly, because of the small level of social segregation in sparsely populated areas, parents may not have to develop strategies to avoid sending their children to the nearest school. Other schools in the area are quite similar in terms of social composition. Finally, in rural areas, the distances are bigger and it is therefore more difficult/costly for a child not to go to the school of her catchment area.

Surprisingly, the Paris agglomeration is not the UA where the differences between public and private schools are the most pronounced. In $2016,28.82 \%$ of the observed social segregation was due to the social gap between the two sectors, compared to almost $40 \%$ in medium-size UAs with more than 50,000 and less than 100,000 inhabitants. The contribution of public/private differences in social segregation is even lower for other large UAs (with more than 
200,000 inhabitants, Paris being excepted). Overall, the pattern of $M(c(X) \cup c(Y))$ with respect to the size of the UA is somewhat "hump-shaped". To our knowledge, this stylized fact has not previously been identified. The problem of social segregation and the role of the private sector are generally seen as being confined to large municipalities in France (see for instance Givord et al., 2016a). Our results show that this view is misleading: the public/private gap is a much broader problem, and particularly acute in medium-size UAs. While the level of social segregation is not so high (0.1027 in 2016 compared with almost twice as much in Paris), the supply of private schools in these UAs is higher than the national level (25.23\% in 2016) and the efforts made by parents to avoid the public school in their catchment area seem to be even stronger than in large urban areas.

Table 4a. Cross-sector Differences by UA Size

\begin{tabular}{|c|c|c|c|c|c|c|}
\hline Measure & \multicolumn{2}{|c|}{$M$} & \multicolumn{2}{|c|}{$M(c(X) \cup c(Y))$} & \multicolumn{2}{|c|}{$\%$ private } \\
\hline Year & 2004 & 2016 & 2004 & 2016 & 2004 & 2016 \\
\hline Rural & 0.0605 & 0.0639 & $3.96 \%$ & $3.91 \%$ & $13.95 \%$ & $12.76 \%$ \\
\hline $\mathrm{UA}<5,000 \mathrm{inh}$ & 0.0578 & 0.0606 & $3.54 \%$ & $4.94 \%$ & $14.30 \%$ & $14.49 \%$ \\
\hline $\mathrm{UA} \in[5,000 ; 10,000] \mathrm{inh}$ & 0.0617 & 0.0762 & $3.64 \%$ & $6.78 \%$ & $18.60 \%$ & $19.45 \%$ \\
\hline $\mathrm{UA} \in[10,000 ; 20,000] \mathrm{inh}$ & 0.0634 & 0.0764 & $11.89 \%$ & $19.85 \%$ & $20.37 \%$ & $22.05 \%$ \\
\hline $\mathrm{UA} \in[20,000 ; 50,000] \mathrm{inh}$ & 0.0847 & 0.0947 & $17.30 \%$ & $30.51 \%$ & $20.61 \%$ & $21.74 \%$ \\
\hline $\mathrm{UA} \in[50,000 ; 100,000] \mathrm{inh}$ & 0.1020 & 0.1027 & $23.01 \%$ & $39.19 \%$ & $23.36 \%$ & $25.23 \%$ \\
\hline $\mathrm{UA} \in[100,000 ; 200,000] \mathrm{inh}$ & 0.1196 & 0.1241 & $17.85 \%$ & $31.36 \%$ & $21.49 \%$ & $24.70 \%$ \\
\hline $\mathrm{UA} \in[200,000 ; 2,000,000] \mathrm{inh}$ & 0.1552 & 0.1632 & $12.95 \%$ & $24.20 \%$ & $23.69 \%$ & $25.89 \%$ \\
\hline Paris Agglomeration & 0.1878 & 0.1975 & $19.18 \%$ & $28.82 \%$ & $18.48 \%$ & $20.12 \%$ \\
\hline France & 0.1253 & 0.1306 & $11.31 \%$ & $18.99 \%$ & $19.90 \%$ & $21.09 \%$ \\
\hline
\end{tabular}

Source: Base Centrale de Scolarité - Authors' calculations. Note: $M$ is the level of the mutual information index $M(c(X) \cup c(Y))$ is the level of segregation between the public sector $X$ and the private sector $Y$, and both are taken as a whole. \% private is the share of students enrolled in a private school.

Between 2004 and 2016, the dynamics of $M$ and $M(c(X) \cup c(Y))$ were rather homogeneous with respect to the UA size. $M$ has increased very slightly in almost each range of UA size. The contribution of differences between the public and the private sectors have increased considerably (from $19.28 \%$ to $28.82 \%$ in the Paris Agglomeration for example), except for in the rural sector where $M(c(X) \cup c(Y))$ remained almost constant. Interestingly, the growth rate is even higher in medium UAs (between 50,000 and 100,000 inhabitants) where the initial level of $M(c(X) \cup c(Y))$ was 
already high. This confirms that the school sector's contribution to segregation is mostly an issue for medium-sized urban areas.

Table $4 \mathrm{~b}$ proposes a new decomposition of cross-sector differences, according to the urban/rural nature of the municipality this time. We compare the values of $M$ and $M(c(X) \cup c(Y))$ in rural areas, isolated municipalities, suburban municipalities and municipality-center municipalities. The results thus complete those of the preceding table; in particular, the distinction between municipality centers and suburbs may be crucial for social segregation: in large UAs, the best (public) schools are often located in municipality centers.

As expected, the level of social segregation is higher in municipality-center and suburban municipalities (even slightly higher in suburbs) than in rural areas or isolated municipalities. Over the period considered, $M$ has increased modestly in each category. However, we observe important differences in the contribution of the school sector. In 2016, $M(c(X) \cup c(Y))$ was below $10 \%$ for rural areas and isolated municipalities, and above $20 \%$ in non-isolated municipalities. The public/private discrepancies are even more pronounced in municipality centers than in suburbs. Hence, once again, the contribution of $M(c(X) \cup c(Y))$ is not at its highest level in the most segregated municipalities. There is an important literature in France on the strength of social disparities within suburbs (see for instance Van Zanten, 2001, Préteceille, 2006 or Oberti, 2007). Our results support this literature on the whole: $M$ is higher in the suburbs than in municipality centers. Yet the public-private disparities are more important in the municipality centers.

Table 4b. Cross-Sector Differences by Urban Type

\begin{tabular}{|c|c|c|c|c|c|c|}
\hline \multirow{2}{*}{$\begin{array}{l}\text { Measure } \\
\text { Year }\end{array}$} & \multicolumn{2}{|c|}{$M$} & \multicolumn{2}{|c|}{$M(c(X) \cup c(Y))$} & \multicolumn{2}{|c|}{$\%$ private } \\
\hline & 2004 & 2016 & 2004 & 2016 & 2004 & 2016 \\
\hline rural areas & 0.0605 & 0.0639 & $3.96 \%$ & $3.91 \%$ & $13.95 \%$ & $12.76 \%$ \\
\hline isolated municipalities & 0.0683 & 0.0731 & $5.72 \%$ & $9.73 \%$ & $17.61 \%$ & $19.35 \%$ \\
\hline suburban municipalities & 0.1445 & 0.1470 & $11.98 \%$ & $20.90 \%$ & $14.46 \%$ & $16.31 \%$ \\
\hline center municipalities & 0.1313 & 0.1382 & $16.07 \%$ & $26.52 \%$ & $25.86 \%$ & $27.69 \%$ \\
\hline France & 0.1253 & 0.1306 & $11.31 \%$ & $18.99 \%$ & $19.90 \%$ & $21.09 \%$ \\
\hline
\end{tabular}

Source: Base Centrale de Scolarité - Authors' calculations. Note: $M$ is the level of the mutual information index. $M(c(X) \cup c(Y))$ is the level of segregation between the public sector $X$ and the private sector $Y$, both taken as a whole.

$\%$ private is the share of students enrolled in a private school

Figure 3 provides another geographical view of differences between the public and the private sectors. The two 
maps give the value (in absolute terms, not as a percentage) of $M(c(X) \cup c(Y))$ for each département in 2004 and 2016 . These maps confirm how $M(c(X) \cup c(Y))$ is spatially heterogeneous. In 2004, the amount of social segregation due to inter-sectoral differences was especially high in the north of France, as well as in the Paris agglomeration. Some of these northern départements do not have an important UA and are partly rural (for instance, Arras with a population of 130,000 is the main agglomeration of the Pas-de-Calais département, and has a value of $M(c(X) \cup c(Y))$ as high as 0.07). Inter-sectoral segregation is therefore not necessarily an effect related to the degree of urbanization. Accordingly, in many administrative districts with large UAs (the Rhône département including the Lyon UA or the Bouches-duRhône département including the Marseille UA), the inter-sectoral segregation level is not above the national average. This result is all the more surprising since, as shown in Figure 1, these highly urbanized administrative districts are those with the highest levels of social segregation. It thus seems that for 2004 the inter-sectoral heterogeneity was, to some extent, a regional question. In 2016, the situation had changed; $M(c(X) \cup c(Y))$ was also high in many other districts apart from in northern France. Inter-sectoral segregation levels are above the national average in most of the districts including important UAs (Paris, Lille, Lyon, Marseille, Nice, Strasbourg and, to a lesser extent, Toulouse and Bordeaux). Hence, the growth in inter-sectoral segregation has not been spatially uniform during the period considered: $M(c(X) \cup c(Y))$ has grown much faster in large or medium UAs than in rural areas. This result supports those detailed in Table 4a: $M(c(X) \cup c(Y))$ doubled (from 12\% to about 24\%) between 2004 and 2016 in agglomerations with more than 200,000 inhabitants.

[ Insert Figure 3 here, Map of France : $M(c(X) \cup c(Y))$ by département ]

\section{F Spatial Decomposition of Inter-Sector Segregation: Heterogeneity is Stronger Locally}

To deepen our spatial analysis, we now exploit the nested decomposability property (equation B.5) of the mutual information index $M$. Actually, at this stage, we only used the simple SSD property (equation B.3): the value of $M(c(X) \cup c(Y))$ at a given scale (either national or local) is compared to the value of $M$ at the same scale. We found that, whatever the chosen scale, $M(c(X) \cup c(Y))$ contributes significantly to $M$. For example, at the national level, $M(c(X) \cup c(Y))$ represents nearly $19 \%$ of $M$. However, this result is fragile and requires robustness tests. The national value of $M(c(X) \cup c(Y))$ is not necessarily interesting per se: it depends on the differences in social composition between public and private middle schools that are potentially geographically very distant from each other. The differences between public and private schools are likely to reflect differences in social composition across distant regions. Family 
decisions about choosing between the public and private sectors for their children's schooling are on a much smaller scale (within-LEA, within-UA, maybe even within-municipality for some families). So we would like to calculate the contribution of local $M(c(X) \cup c(Y))$ to the national value of $M$.

More precisely, we want to know if the differences between the public and the private sector are still significant at a local level. In fact, it is theoretically possible to observe a high value of $M(c(X) \cup c(Y))$ at the national level, but a very low value at a local level. To see why, let's take an example: suppose that there are only two geographical areas $\mathrm{A}$ and $\mathrm{B}$ (two regions for instance) in the country, each with the same number of schools. Region $\mathrm{A}$ is rich and region $\mathrm{B}$ is poor. At the national level, there are $50 \%$ private schools and $50 \%$ public schools. We first calculate the national $M(c(X) \cup c(Y))$. Suppose that we find $M(c(X) \cup c(Y))>0$ (i.e., the national social distributions of public and private schools are not the same). Next, we would like to estimate the within-region value of $M(c(X) \cup c(Y))$. This will depend crucially on the distribution of public and private schools in each region. If there are $75 \%$ rich private schools and $25 \%$ rich public schools in Region A and $25 \%$ poor private schools and $75 \%$ poor public schools in Region B, then the within-region $M(c(X) \cup c(Y))$ will be zero: within each region, public and private schools are similar. However, the national $M(c(X) \cup c(Y))$ will be strictly positive: throughout the whole country, three private schools out of four are rich, compared to only one out of four public schools. But this only results from social background differences between the two regions and not from local enrollment decisions. In this case, the existence of the private sector does not create an additional social divide: the parents of each region send their children to the public or private sector indifferently. ${ }^{14}$

So, if the private sector is focused in a particular region, then the within-region $M(c(X) \cup c(Y))$ will be above its national counterpart. By contrast, if private and public schools are more evenly distributed across regions, then the within-region $M(c(X) \cup c(Y))$ might be above national $M(c(X) \cup c(Y)) .{ }^{15}$ In this case, it means that private and public schools differ locally and this public/private gap will result from the local strategies of the families (seeking to escape the local public school) or by school heads (wanting to attract students with advantaged or highly advantaged backgrounds). Here, the existence of the private sector can be seen as creating an additional social divide in the region.

The difference between these two situations (within-region $M(c(X) \cup c(Y)$ )below or above national $M(c(X) \cup$ $c(Y)))$ is crucial : in Tables $4 \mathrm{a}$ and $4 \mathrm{~b}$, we saw that the share of private schools is much higher in large UAs, and especially in UA centers. On average, these areas are also richer than rural areas, small municipalities or suburban municipalities. We also saw in the previous section that rural or sparsely-populated areas and so LEAs with few or

\footnotetext{
${ }^{14}$ However, there is still a question of endogeneity: why are more private schools established in the rich region?

${ }^{15}$ In case of a totally even distribution of public and private schools across regions, the within-region $M(c(X) \cup c(Y))$ will be mechanically above the national $M(c(X) \cup c(Y))$, due to the intrinsic properties of the segregation index.
} 
no major agglomerations had relatively fewer private schools. So we need to see if the public/private social gap is just the consequence of the higher concentration of private schools in rich areas or if local differences exist between the two sectors. Such information may be relevant in the context of a policy aimed at reducing the levels of segregation, if the authorities seek to evaluate the proper geographical scope of the policy.

As a first step, we study inter-sectoral differences among agglomerations of the same size range. Our results are summarized in Table 5a. Thanks to the SSD property of $M$, it is easy to calculate these values at the within-LEA, within-UA size, etc. levels. Some of the results in this table have been explained previously: the level of total social segregation in France and the share of this segregation due to discrepancies between UAs of different sizes. The last two columns of the table give the share of the total segregation due to differences between the public and the private sectors (i.e., $M(c(X) \cup c(Y)))$ within UAs of the same size range. Actually, it has increased sharply since 2004, from $13 \%$ to almost $22 \%$. This is higher than the national results. As shown by Figure 2, $M(c(X) \cup c(Y))$ at the national level was three percentage points lower in 2016. Cross-sector differences seem to be even more prominent within comparable agglomerations than overall.

Table 5a. Decomposition of Cross-Sector Differences by UA Size

\begin{tabular}{|c|c|c|c|c|c|c|}
\hline \multirow[b]{2}{*}{ Year } & \multicolumn{2}{|c|}{ Total } & \multicolumn{2}{|c|}{ between-UA size } & \multicolumn{2}{|c|}{$\begin{array}{l}\text { within-UA size, } \\
\text { between-sectors }\end{array}$} \\
\hline & 2004 & 2016 & 2004 & 2016 & 2004 & 2016 \\
\hline Segregation & 0.1253 & 0.1306 & $9.97 \%$ & $8.98 \%$ & $13.22 \%$ & $21.96 \%$ \\
\hline
\end{tabular}

The first two columns give the national value of $M$ in 2004 and 2016

The four other columns give $M(c(X) \cup c(Y))$ for different scales and years

In a second step, we further narrow the geographical scale by adding the LEA level. Hence, we refine this analysis by nesting different geographical scales. We first reproduce the dynamics of the share of $M$ due to gaps across LEAs. As already shown in Table 2, it increased between 2004 and 2016. Interestingly, it appears that the level of segregation across UAs of the same size is much lower when estimated within the same LEAs than directly at the national level ( $7.30 \%$ instead of $8.98 \%$ in 2016). This is probably due to a strong correlation of the LEA and UA size variables in terms of social background distribution. Schools of different UAs are much closer to each other in the same LEA than at the national level. These results validate the intuition that a relatively disaggregated geographical approach of the private sector contribution to segregation at school is relevant. 
Table 5b. Decomposition of Cross-Sector Differences by LEA and UA size

\begin{tabular}{|c|c|c|c|c|c|c|c|c|}
\hline \multirow[b]{2}{*}{ Year } & \multicolumn{2}{|c|}{ Total } & \multicolumn{2}{|c|}{ between-LEAS } & \multicolumn{2}{|c|}{$\begin{array}{l}\text { within-LEAs, } \\
\text { between-UA size }\end{array}$} & \multicolumn{2}{|c|}{$\begin{array}{l}\text { within-(LEA and UA size) } \\
\text { between-sectors }\end{array}$} \\
\hline & 2004 & 2016 & 2004 & 2016 & 2004 & 2016 & 2004 & 2016 \\
\hline Segregation & 0.1253 & 0.1306 & $16.33 \%$ & $17.63 \%$ & $8.50 \%$ & $7.30 \%$ & $14.61 \%$ & $22.17 \%$ \\
\hline
\end{tabular}

The first two columns give the national value of $M$ in 2004 and 2016

The six other columns give $M(c(X) \cup c(Y))$ for different scales and years

Hence, choosing a smaller geographical scale does not reduce the contribution of cross-sector differences to total social segregation. In 2016, $M(c(X) \cup c(Y))$ was lower by $19 \%$ at the national level, by $21.96 \%$ within UA size, and by $22.17 \%$ within LEAs and UA sizes. First, this can be seen as a robustness check: it confirms the importance of the contribution of the public/private divide in social segregation. Second, it means that private and publics schools are on average slightly more dissimilar on a local basis than at an overall one. This, at least partly, confirms that families' choices between public and private education are made locally: the decision must be made between the public school corresponding to the family's catchment area and a nearby private school. Consequently, if the private school enrolls a higher proportion of advantaged or highly advantaged students, the local public school will mechanically host a proportion of intermediate or disadvantaged students which is higher than the local average. Hence, local differences between public and private schools are strong and the contribution of local $M(c(X) \cup c(Y))$ to total segregation is high. The competition between schools' sectors generates additional segregation locally.

Finally, we also reproduce the same decomposition of cross-sector differences, but replacing the UA size with the municipality, a much smaller geographic level. The results are hardly novel: the within-(LEA and municipality), between-sectors value of $M(c(X) \cup c(Y))$ was still slightly above $22 \%$ in 2016 . This was very close to the level between sectors within LEAs and UAs of similar size (see the results of Table 5b). Hence, the level of segregation between sectors ceased to increase as we reduce the spatial scale to the municipality level. It was close to $19 \%$ at the national level, close to $22 \%$ at the UA-size level, above $22 \%$ at the within LEA and UA-size level, but still close to $22 \%$ at the municipality level. The more enrollment strategies are local, the higher the local level of segregation. This shows that while the school enrollment strategies are indeed local, they are not limited to a municipality, but may extend to neighboring municipalities. 
Table 5c. Decomposition of Cross-Sector Differences by LEA and Municipality

\begin{tabular}{|c|c|c|c|c|c|c|c|c|}
\hline \multirow[b]{2}{*}{ Year } & \multicolumn{2}{|c|}{ Total } & \multicolumn{2}{|c|}{ between-LEAS } & \multicolumn{2}{|c|}{$\begin{array}{l}\text { within-LEAs, } \\
\text { between-municipality }\end{array}$} & \multicolumn{2}{|c|}{$\begin{array}{l}\text { within-LEA and municipality } \\
\text { between-sectors }\end{array}$} \\
\hline & 2004 & 2016 & 2004 & 2016 & 2004 & 2016 & 2004 & 2016 \\
\hline Segregation & 0.1253 & 0.1306 & $16.33 \%$ & $17.63 \%$ & $4.19 \%$ & $3.65 \%$ & $14.79 \%$ & $22.15 \%$ \\
\hline
\end{tabular}

The first two columns give the national value of $M$ in 2004 and 2016

The six other columns give $M(c(X) \cup c(Y))$ for different scales and years

\section{G Conclusion}

In this paper, we proceeded with a geographical and urban analysis of the contribution of the differences between the public and the private sectors to social segregation in French middle schools. We use the mutual information index and exploit its additive decomposability properties to break down spatially the role of the two sectors in segregation. We show that the contribution of public/private discrepancies is higher in regions in the north of France, as well as in medium-sized UAs and municipality centers. Yet these geographical areas are not those where social segregation is the highest, nor are they areas in which the private sector is commonly regarded as the main cause of segregation. The presence of private sector schools explains only a rather limited part of the social segregation found in Paris or in large UAs. Moreover, the gaps between the public and the private sectors are stronger at the local level. This confirms the idea that the private sector is a tool for circumventing France School Map and that it creates additional social differences at small spatial levels.

\section{References}

[1] Allen R (2007) Allocating pupils to their nearest secondary school: The consequences for social and ability stratification. Urban Studies, 44(4): 751-770.

[2] Andre-Bechely L. (2007). Finding Space and Managing Distance: Public School Choice in an Urban California District. Urban Studies, Vol. 44, No. 7, 1355-1376

[3] Bernelius, V. H. \& Vaattovaara, M. K. 2016 Choice and segregation in the "most egalitarian" schools: Cumulative decline in the urban schools and neighbourhoods of Helsinki, Finland, Urban Studies. 53(15), p. 3155-3171. 
[4] Burgess S., Wilson D., Lupton R. (2005). Parallel Lives? Ethnic Segregation in Schools and Neighbourhoods,. Urban Studies, 42(7),1027-1056.

[5] Butler, T. and Hamnett, C. (Eds) (2007) Special Issue on 'The Geography of Education', Urban Studies, 44(7).

[6] Cohen-Zada D, Sander W (2008) Religion, religiosity and private school choice: Implication for estimating the effectiveness of private schools. Journal of Urban Economics, 64: 85-100.

[7] Fack G. and J. Grenet (2010), When do Better Schools Raise Housing Prices ? Evidence from Paris Public and Private Schools, Journal of Public Economics, 94(1-2), 59-77.

[8] Fischer C.S., Stockmayer G., Stiles J. and M. Hout (2003), Distinguishing the Geographic Levels and Social Dimensions of U.S. Metropolitan Segregation, 1960-2000, Demography, 41(1), 37-59.

[9] Frankel D.M. and O. Volij, (2011), Measuring School Segregation, Journal of Economy Theory, 146(1), 1-38.

[10] Gamsu S. (2016). Moving up and moving out: The re-location of elite and middle-class schools from central London to the suburbs, Urban Studies, 53(14) 2921-2938.

[11] Givord P., Guillerm M., Monso O., Murat F. (2016a) Comment mesurer la ségrégation dans le système éducatif ? Une étude de la composition sociale des collèges français, Education E Formations, 91, 21-51.

[12] Givord P., Guillerm M., Monso O., Murat F. (2016b) La ségrégation sociale entre les collèges. Quelles différences entre public et privé, aux niveaux national, académique et local ?, Education 6 Formations, 91, 53-76.

[13] Gordon I. and Monastiriotis V.(2006), Urban Size, Spatial Segregation and Inequality in Educational Outcomes, Urban Studies, Vol. 43, No. 1, 213-236.

[14] Gramberg P. (1998) School Segregation: The Case of Amsterdam, Urban Studies, 35(3), 547-564.

[15] Gulson, K. N. (2007) Repositioning schooling in inner Sydney: urban renewal, an education market and the 'absent presence' of the middle classes, Urban Studies, 44(7), 1377-1391.

[16] Hamnett C., Ramsden M. and Butler T. (2007).Social Background, Ethnicity, School Composition and Educational Attainment in East London, Urban Studies, 44 (7), 1255-1280.

[17] Lees, L. and Ley, D. (Eds) (2008) Special Issue on Gentrification and Public Policy, Urban Studies, 45(12).

[18] Lee B.A., Reardon S.F., Firebaugh G., Farrell C.R., Matthews S.A. and D. O'Sullivan (2008), Beyond the Census Tract: Patterns and Determinants of Racial Segregation at Multiple Geographic Scales, American Sociological Review, 73(5), 766-791. 
[19] Lichter D.T., Parisi D., and M.C. Taquino (2015), Toward a New Macro Segregation? Decomposing Segregation within and between Metropolitan Cities and Suburbs, American Sociological Review, 80(4), 843-873.

[20] Ly S.-T., Maurin E., Riegert A. (2014), La mixité sociale et scolaire en Ile-de-France : le rôle des établissements, Report IPP (Institut des Politiques Publiques), $\mathrm{n}^{\circ} 4$.

[21] Ly S.-T., Riegert A. (2015), Mixité sociale et scolaire et ségrégation inter et intra établissement dans les collèges et lycées français, CNESCO.

[22] Massey D.S. and N.A. Denton (1988), The Dimension of Residential Segregation, Social Forces, 67(2), 281-315.

[23] Merle P. (2012), La ségrégation scolaire, Repère, La découverte.

[24] Murnane R. J. and Reardon S. F. (2017), Long term trends in private school enrollments by family income. NBER Working Paper, 23571.

[25] Oberti M. (2007), L'école dans la ville. Ségrégation - mixité - carte scolaire, Presses de Sciences Po, Sociétés en Mouvement.

[26] OECD (2011). Private schools: Who benefits? PISA in Focus, 7.

[27] Poucet B. (2012), L'enseignement privé en France, Que-sais-je ?, Presse Universitaire de France.

[28] Préteceille E. (2006), La ségrégation sociale a-t-elle augmenté. La métropole parisienne entre polarisation et mixité, Sociétés contemporaines, 62, 69-93.

[29] Reardon S.F., and G. Firebaugh (2002), Measures of Multigroup Segregation, Sociological Methodology, 32(1), $33-67$.

[30] Reardon S.F., Farrell C.R., Matthews S.A., O’Sullivan D., Bischoff K., and G. Firebaugh (2009), Race and Space in the 1990s: Changes in the Geographic Scale of Racial Residential Segregation, 1990-2000, Social Science Research, 38(1), 55-70.

[31] Thélot C. (2013), Les missions de l'école en France, contribution de l'école catholique, Revue Projet, 333(2), 4-12.

[32] Thrupp M. (2007), School Admissions and the Segregation of School Intakes in New Zealand Cities, Urban Studies, 44(7), 1393-1404.

[33] Webber R. and Butler T. (2007).Classifying Pupils by Where They Live: How Well Does This Predict Variations in Their GCSE Results? Urban Studies, 44(7), 1229-1253. 
[34] Van Zanten A. (2001), L'école de la périphérie ? Scolarité et ségrégation en banlieue, Paris, PUF. 


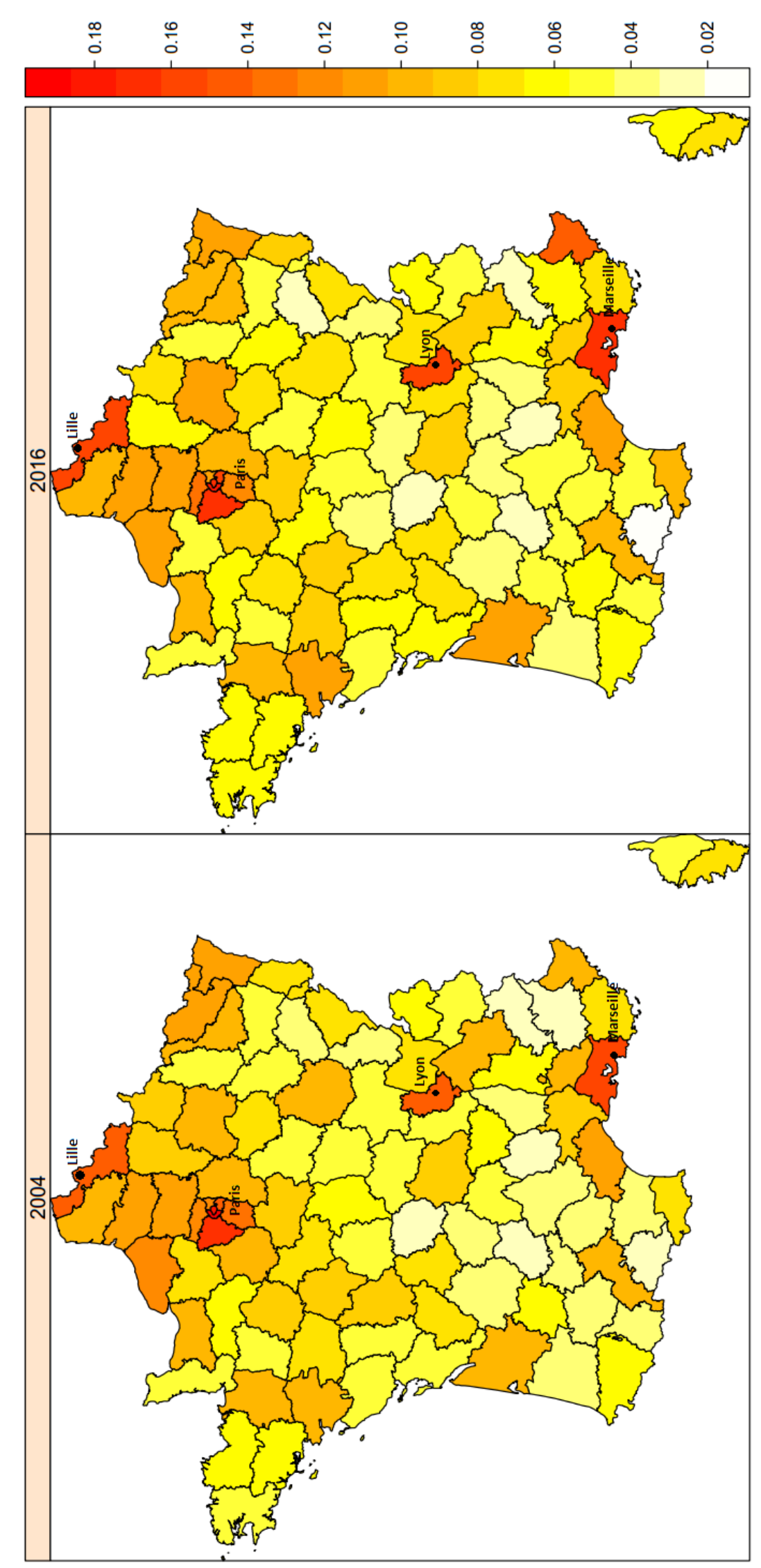

Figure 1: Level of segregation $M$ by department 


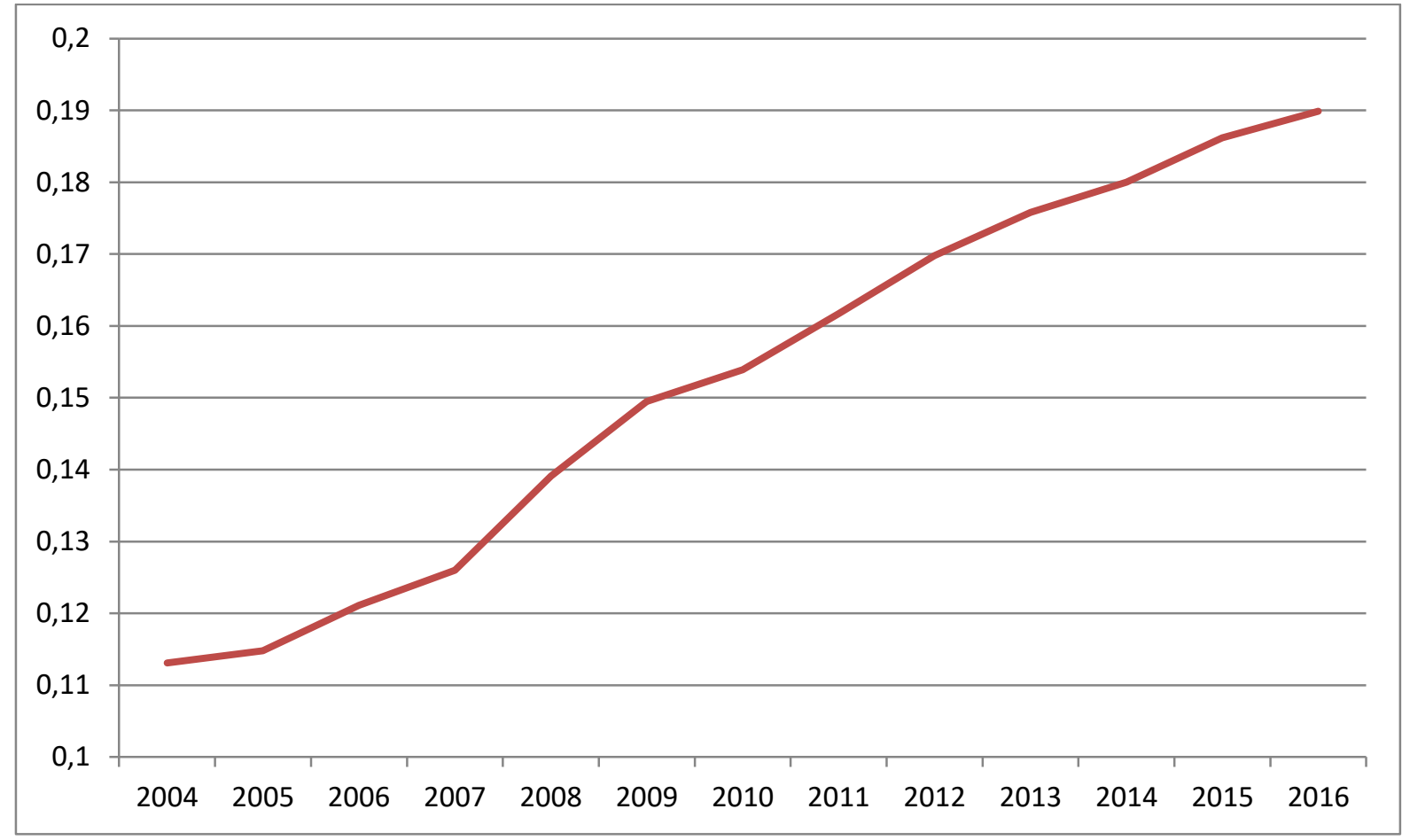

Figure 2: Share (\%) of the total segregation due to differences between the private $(X)$ and the public $(Y)$ sectors. This corresponds to expression $M(c(X) \cup c(Y))$ in equation (B.3). Source: Base Centrale de Scolarité - Authors' calculations 


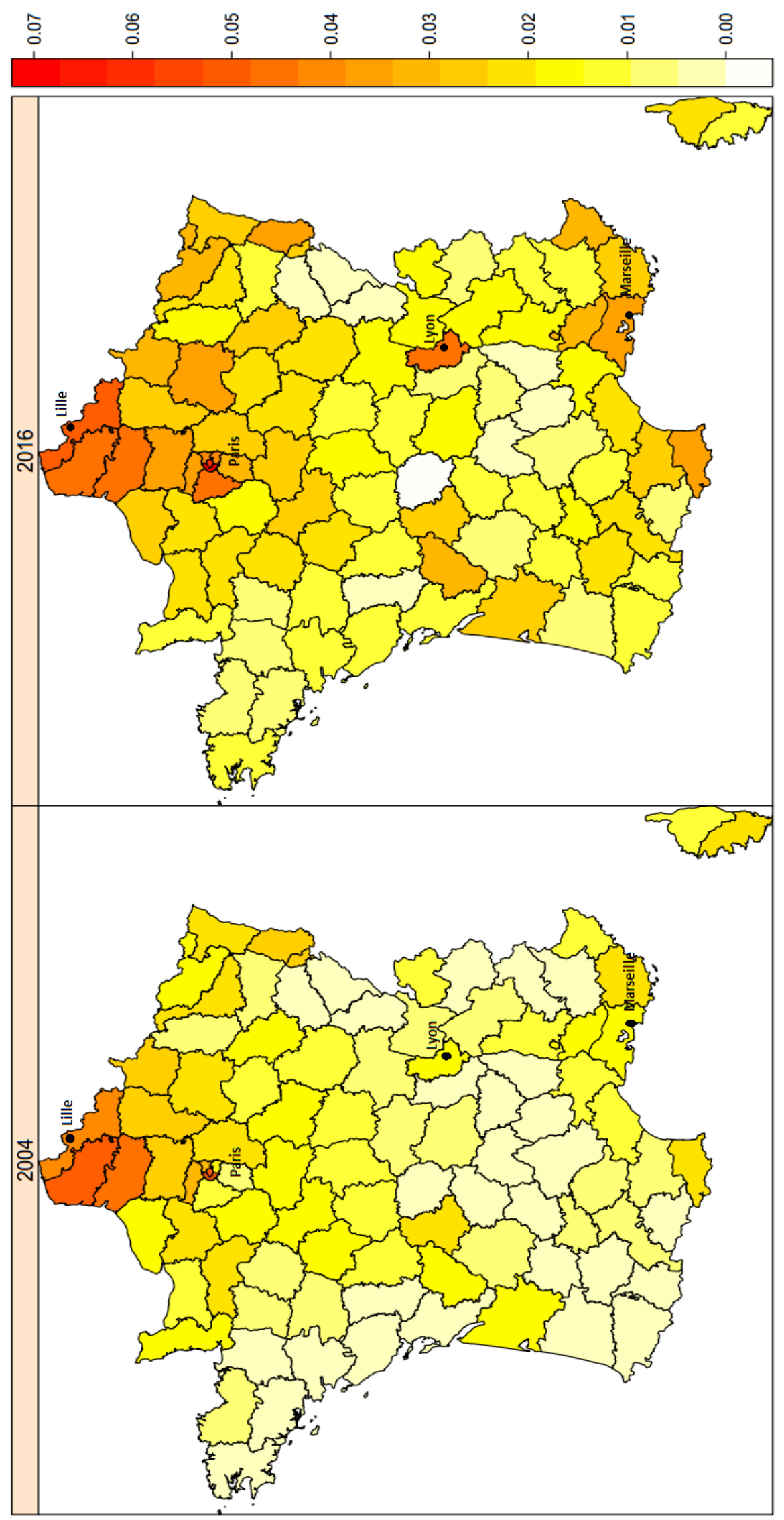

Figure 3: Level of $M(c(X) \cup c(Y))$ by département 